\title{
Evaluation of the Preventive and Therapeutic Activities of Tridax procumbens against Hyperglycemia and Hyperlipidemia Induced in Wistar Rats
}

\author{
Jean-Baptiste Amagbegnon', Omédine Koukoui', Pascal C. Agbangnan', Santorin Seton', \\ Mansouratou Betira' ${ }^{1}$, Sedami Medegan'3 , Laura Loko4, Victorin Dougnon'5 , Luc Djogbenou', \\ Alphonse Sezan ${ }^{7}$
}

\author{
${ }^{1}$ Laboratory of Animal Physiology, Cellular Signalisation and Pharmacology, University of Sciences Technologies, Engineering \\ and Mathematics, Dassa Zoume, Benin \\ ${ }^{2}$ Laboratory of Study and Research in Applied Chemistry, Unity of Research and Molecular Interactions (URIM/LERCA/UAC), \\ Cotonou, Benin \\ ${ }^{3}$ Medicinal and Organic Chemistry Laboratory, Faculty of Health Sciences, Cotonou, Benin \\ ${ }^{4}$ Laboratory of Applied Entomology, University of Sciences Technologies, Engineering and Mathematics, Dassa Zoume, Benin \\ ${ }^{5}$ Research Unit in Applied Microbiology and Pharmacology of Natural Substances, Research Laboratory for Applied Biology, \\ Polytechnic School of Abomey-Calavi, University of Abomey-Calavi, Abomey-Calavi, Benin \\ ${ }^{6}$ Laboratory of Infectious Vector Borne Diseases, Regional Institute of Public Health, University of Abomey-Calavi, \\ Abomey-Calavi, Benin \\ ${ }^{7}$ Laboratory of Biomembranes and Cellular Signalisation, University of Abomey-Calavi, Cotonou, Benin \\ Email: omedine24@gmail.com
}

How to cite this paper: Amagbegnon, J.-B., Koukoui, O., Agbangnan, P.C., Seton, S., Betira, M., Medegan, S., Loko, L., Dougnon, V., Djogbenou, L. and Sezan, A. (2021) Evaluation of the Preventive and Therapeutic Activities of Tridax procumbens against Hyperglycemia and Hyperlipidemia Induced in Wistar Rats. Pharmacology \& Pharmacy, 12, 127-140.

https://doi.org/10.4236/pp.2021.127012

Received: May 26, 2021

Accepted: July 17, 2021

Published: July 20, 2021

\begin{abstract}
From the Asteraceaes family, Tridax procumbens is a wild species frequently found in fields, meadows and roadsides. It is traditionally used to treat yellow fever, typhoid fever, high blood pressure and diabetes. In this work we used the hydro-ethanolic extract of the leaves and stems of the plant and also the fractions of this extract to determine the preventive and therapeutic activities of the plant against obesity, hyperglycemia and hyperlipidemia. The yields of the fractions obtained by decantation of the hydro-ethanolic extract are respectively $0.160 \%$ with hexane, $0.073 \%$ with dichloromethane, $0.09 \%$ with diethyl ether and $0.150 \%$ with ethyl acetate. Hyperglycemia and hyperlipidemia were induced in the rats submitted to a fatty and sweet diet for 28 days. Our results showed a significant increase in glycemia, weight and triglyceride level in rats that were subjected to the diet. On the other hand, the rats treated with the dose of $500 \mathrm{mg} / \mathrm{kg}$ of body weight of Tridax procumbens extract during the induction showed a reduction in weight gain and an absence of increase
\end{abstract}


Copyright $\odot 2021$ by author(s) and Scientific Research Publishing Inc. This work is licensed under the Creative Commons Attribution International License (CC BY 4.0).

http://creativecommons.org/licenses/by/4.0/ in blood sugar and triglyceride levels. The ethyl acetate fraction of Tridax procumbens extract administered to fatty and hyperglycemic rats at $50 \mathrm{mg} / \mathrm{kg}$ of body weight for 14 days did not induce change in the blood sugar and triglycerides level of fatty and hyperglycemic rats. If it seems obvious that the extract of Tridax procumbens prevents hyperglycemia and hyperlipidemia, the ethyl acetate fraction does not seem to have a therapeutic effect.

\section{Keywords}

Tridax procumbens, Prevention, Treatment, Hyperglycemia, Hyperlipidemia

\section{Introduction}

The prevalence of Non-Communicable Diseases (NCDs) such as diabetes, cardiovascular diseases and cancer continues to increase worldwide and reducing it is one of the great challenges of the 21st century. In 2008, NCDs were thought to have caused 36 million deaths, or $63 \%$ of all deaths worldwide; $80 \%$ ( 29 million deaths) occurred in low-income countries [1]. Mortality from NCDs is expected to increase by a further $17 \%$ over the next 10 years [1]. It is especially among the poor and underprivileged that the incidence of these diseases is increasing rapidly, further widening the health gaps in these countries. Herbal medicine still largely based on recipes and empirical exploitations, however, remains the most widely used method as an alternative to conventional chemical medication to treat or prevent many contemporary chronic diseases [2] [3] [4]. Tridax procumbens is a plant species in the Asteraceae family, it is native to Central and South America but has been introduced to tropical, subtropical and temperate regions around the world [5]. Several researchers have reported that it has immunomodulatory [6], antidiabetic [7], antihepatotoxic [8], antioxidant [9], antimicrobial, anti-bacterial [10], antiplasmodium [11], and anti-cancerous [12] properties. Previous work have shown that Tridax Procumbens hydroethanolic extract is not toxic and is a good antioxidant that significantly reduces lipid accumulation in HepG2 cells [13]. The presence of several secondary metabolites including flavonoids, tannins, sterols, reducing sugars, triterpernoids [12] [13] [14]; minerals like potassium and calcium and vitamins E and K1 [15] could explain the effects of the plant against diabetes and cardiovascular diseases. The anti-hyperglycemic and anti-hyperlipidic activities of the Beninese species of the plant were evaluated in healthy Wistar rats given a normal diet. The results did not show any anti-hyperglycemic activity, but cholesterol lowering and triglyceride lowering activities were noted [16]. In this work we studied the effects of the hydroethanolic extract of Tridax procumbens on glycemia, cholesterol and triglyceride levels of Wistar rats subjected to a fatty and sweet diet for 28 days. Then we treated the hyperglycemic and fatty rats resulting from this diet with the ethyl acetate fraction made from the hydroethanolic 
extract of $T$. procumbens.

\section{Materials and Methods}

\subsection{Materials}

\subsubsection{Collection of Tridax procumbens Plants}

T. procumbens plants were collected at Abomey Calavi a small city of Benin. A specimen was deposited in the National Herbarium of the Department of Botany, Abomey-Calavi University. Samples were dried in shade at room temperature $\left(25^{\circ} \mathrm{C}\right)$ until stabilization of their mass and then pulverized into coarse powder.

\subsubsection{Animal Material}

The experimental animals are male and female Wistar rats weighing between 150 and $250 \mathrm{~g}$. All animals have health status of SPF (specific pathogen Exempt). Work on wistar rats were authorized by the national committee of ethics of Benin science academy. Upon receipt, the rats were randomly placed in groups of five (5) in standard cages for a period of acclimatization (2 weeks) before being used in various experiments. During this period the animals had free access to food and water and remained kept at constant temperature $(22 \pm 2)^{\circ} \mathrm{C}$. They were subjected to a light/dark cycle $12 \mathrm{~h} / 12 \mathrm{~h}$. The dark phase of the cycle begins at $12 \mathrm{~h}$ and different experiences have always been held from 11AM to 6PM due to the nocturnal activity (active phase) of rats.

\subsection{Methods}

\subsubsection{Tridax procumbens Leaves and Stems Extraction}

All samples were ground in a commercial coffee grinder for extraction. The mixture ethanol-water $50 \%(\mathrm{v} / \mathrm{v})$ was used as extraction solvent. The extract was concentrated in vacuo using a rota vapor and the yield $(Y)$ was calculated by the formula below:

$$
Y(\%)=(\text { Mass of extract }) /(\text { Mass of plant material used }) \times 100 \text {. }
$$

\subsubsection{Fraction Production}

- Liquid-liquid extraction

The fractions are obtained by successive partitions with increasing polarity solvent (hexane, dichloromethane, ethyl ether, ethyl acetate and butanol) following the diagram described by Koudoro et al., 2014 [17].

- Liquid-Solid Extraction

It consists of evaporating at a temperature according to the solvents of polarity, the liquid-liquid extracts using a rotary evaporator. The extracted phase is collected and solidified in an oven at $40^{\circ} \mathrm{C}$.

- Calculation of the yield of the fractions

The yield of the different fractions obtained is calculated according to the formula:

$$
R=\text { mass of fraction/mass of powder } \times 100 \text {. }
$$




\subsubsection{Induction of Hyperglycemia and Hyperlipidemia in Wistar Rats}

Hyperglycemia and hyperlipidemia are induced by adding sweet chips and cookies to their daily diet; they were force-fed with $2 \mathrm{ml}$ of pork fat per day and their drink consisted of $100 \mathrm{mg} / \mathrm{ml}$ sugar water free of charge.

20 rats were divided into (4) groups of five (5) rats. The rats were acclimatized for three (3) weeks.

group 1: 5 negative control rats were fed normally and were force-fed with physiological water.

group 2: 5 positive control rats subjected to the sweet and fatty diet were force-fed with distilled water.

group 3: 5 rats subjected to the sweet and fatty diet were force-fed with physiological water. (untreated rats)

group 4: 5 rats subjected to the sweet and fatty diet were force-fed with 500 $\mathrm{mg} / \mathrm{kg} / \mathrm{BW}$ of Tridax procumbens extract diluted in physiological water (treated rats).

\subsubsection{Rats Weighing and Blood Sampling}

The body weight of the rats were taken on day 0 (D0), D7, D15, D21 and on the 28th day (D28).

The blood of the rats of the groups $(1-4)$ was drawn before treatment at day 0 and day 28 for biochemical parameters assays: Glycemia; Triglycerides; Total cholesterol. The blood samples were taken according to the experimental protocol used by Weiss and al in 2000 [18].

\subsubsection{Determination of Glucose Concentration in the Blood}

It is a colorimetric assay following two coupled enzymatic reactions. A closely specific enzymatic reaction (glucose oxidase) oxidizes glucose present in the sample to gluconic acid and hydrogen peroxide. It serves as the substrate for the peroxidase in a coupled reaction resulting in the oxidation of o-dianisidine to a colored product. The intensity of the color is proportional to the glucose concentration. A capsule of enzymes (glucose oxidase-peroxidase) is dissolved in $100 \mathrm{ml}$ of water followed by $1.6 \mathrm{ml}$ of solution of o-dianisidine. The reagent is ready to use and can be kept several days in the refrigerator. We conducted a blank tube containing only distilled water $(20 \mu \mathrm{l})$, two standard tubes containing $20 \mu \mathrm{l}$ of glucose $(1 \mathrm{~g} / \mathrm{l})$. And then we have prepared two tubes each containing 20 $\mu$ of supernatant (blood plasma) for each sample. $2 \mathrm{ml}$ of reagent was then added into each tube and all placed in an oven at $37^{\circ}$ for 10 minutes. After steaming completed, the absorbance was measured by spectrophotometry at $470 \mathrm{~nm}$, taking as zero the white tube. We kept the average of the two values for duplicate tubes when they are compatible. The glucose concentration is found with the following calculation:

$$
[G]=\text { Do/Dsg } \times \text { Csg }
$$

With: Do $=$ absorbance, Dsg $=$ Do standard glucose, Csg $=$ concentration standard glucose. 


\subsubsection{Determination of Triglycerides Concentration in the Blood [18]}

The triglyceride samples were incubated with the lipoprotein lipase (LPL) and glycerol and fatty acids were released. Glycerol was converted to glycerol 3-phosphate (G3P) and adenosine-5-diphosphate (ADP) by glycerol kinase and ATP. Glycerol 3-phosphate (G3P) was then transformed with glycerol phosphate dehydrogenase (GPO) to dihydroxyacetone phosphate (DAP) and hydrogen peroxide $(\mathrm{H} 2 \mathrm{O} 2)$. Hydrogen peroxide $(\mathrm{H} 2 \mathrm{O} 2)$ reacted with 4-amino-antipyrine (4$\mathrm{AP}$ ) and p-chlorophenol in the presence of peroxidase (POD) to give a red color. The intensity of the color formed is proportional to the amount of triglycerides contained in the serum sample. The absorbance was measured by spectrophotometry at $505 \mathrm{~nm}$, triglycerides concentration is given by the formula: Trygly-cerides rate $(\mathrm{g} / \mathrm{l})=(\mathrm{DOD} / \mathrm{DOE}) \times 2 ; \mathrm{DOD}=$ absorbance of samples, $\mathrm{DOE}=$ absorbance of standard.

\subsubsection{Determination of Total Cholesterol Concentration in the Blood} [19]

Cholesterol and its esters were released from the lipoproteins with detergents. Cholesterol esterase hydrolyzed esters. Peroxide was formed in the subsequent enzymatic oxidation of cholesterol by cholesterol oxidase. Peroxide with phenol and 4-aminoantipyrine produced quinonneimine in the presence of peroxidase. The absorbance of quinonneimine was measured at $505 \mathrm{~nm}$ and is proportional to the concentration of total cholesterol.

Total cholesterol concentration is given by the formula: cholesterol concentration $(\mathrm{g} / \mathrm{l})=(\mathrm{DOD} / \mathrm{DOE}) \times 2 ; \mathrm{DOD}=$ absorbance of samples, $\mathrm{DOE}=$ absorbance of standard.

\subsubsection{Treatment of Fatty and Hyperglycemic Rats with the Ethyl Acetate Fraction of $T$, procumbens Extract}

This phase lasted for 14 days of treatment. Groups 2 and 3 of rats were considered. The last day of the hyperglycemia and hyperlipidemia induction phase was considered to be Day zero (D0) of this phase. Group 2 rats were force-fed with distilled water during the 14 days of treatment. Group 3 rats were force-fed with $50 \mathrm{mg} / \mathrm{Kg}$ of body weight by the fraction during the 14 days. The body weight gain of the rats was taken on D0, D7 and D14. Finally on the 15th day, the blood sample was taken for various biochemical parameters assays.

\subsubsection{Statistic Analysis}

Data were analyzed in R software version 3.6. 1R core team 2019. The paired samples Student $t$ test was used to verify the differences between means. The differences are considered significant at $\mathrm{P} \leq 0.05$.

\section{Results}

\subsection{Yields of Tridax procumbens Fractions}

Hexane and ethyl acetate gave the best yields for the fractions production with Tridax procumbens extract (Table 1). 
Table 1. Yield of different fractions.

\begin{tabular}{cc}
\hline Type of solvent & Yield of extracts \\
\hline Hexane & 1.60 \\
Dichloromethane & 0.073 \\
Diethyl ether & 0.093 \\
Ethyl acetate & 0.150 \\
\hline
\end{tabular}

\subsection{Evaluation of the Preventive Activity of the Hydroethanolic Extract of Tridax procumbens (Tp)}

In order to evaluate the preventive role of the ethanolic extract of $T p$ we induced hyperglycemia and hyperlipidemia in rats for 28 days. During induction a group of rats was treated with $T p$ extract at $500 \mathrm{mg} / \mathrm{kg}$ of body weight.

\subsubsection{Evolution of Rat Weight during Induction of Hyperglycemia and Hyperlipidemia}

Rats body mass increased significantly during induction from day 0 to day 28 in both rat groups. Treatment with Tridax procumbens extract (treated) appeared to slightly decrease rat weight gain from day 7 to day 28 (Figure 1). The weight gain of the rats is 3 times higher in the rats in which the hyperglycemia and the hyperlipidemia were induced (untreated) than in the control rats (Figure 2). Treatment with Tridax procumbens extract reduced this percentage by $3 \%$.

\subsubsection{Evolution of Rat Blood Glucose during Induction of Hyperglycemia and Hyperlipidemia}

During induction, the blood glucose levels of the rats were taken on day 0 (D0) and on day 28(D28) in the different groups of rats (controls, untreated and treated with the Tridax procumbens extract at $500 \mathrm{mg} / \mathrm{Kg}$ of Body Weight).

The blood glucose levels of the rats did not vary significantly in the control rats after the 28 days of induction, however it significantly increased by $50 \%$ in the induced and not treated rats (untreated). As control rats, the blood glucose of the rats induced and treated with Tridax procumbens extract $(500 \mathrm{mg} / \mathrm{Kg}$ of body weight) (treated) did not significantly change from day 0 to day 28 (Figure 3) (were considered statistically significant the difference in the mean at $\mathrm{P} \leq 0.05$ ).

\subsubsection{Evolution of Rat Blood Cholesterol during Induction of Hyperglycemia and Hyperlipidemia}

The cholesterol level did not change significantly during induction in any group of rats (Figure 4) (there is no difference in the mean at $\mathrm{P} \leq 0.05$ ).

\subsubsection{Evolution of Rat Blood Triglyceride during Induction of Hyperglycemia and Hyperlipidemia}

The triglyceride level increased significantly only in the untreated induced rats. We didn't observe a significant increase neither in the control rats, nor in the induced rats treated with the extract of Tridax procumbens at $500 \mathrm{mg} / \mathrm{kg}$ of body weight (Figure 5) (were considered statistically significant the difference in the mean at $\mathrm{P} \leq 0.05)$. 


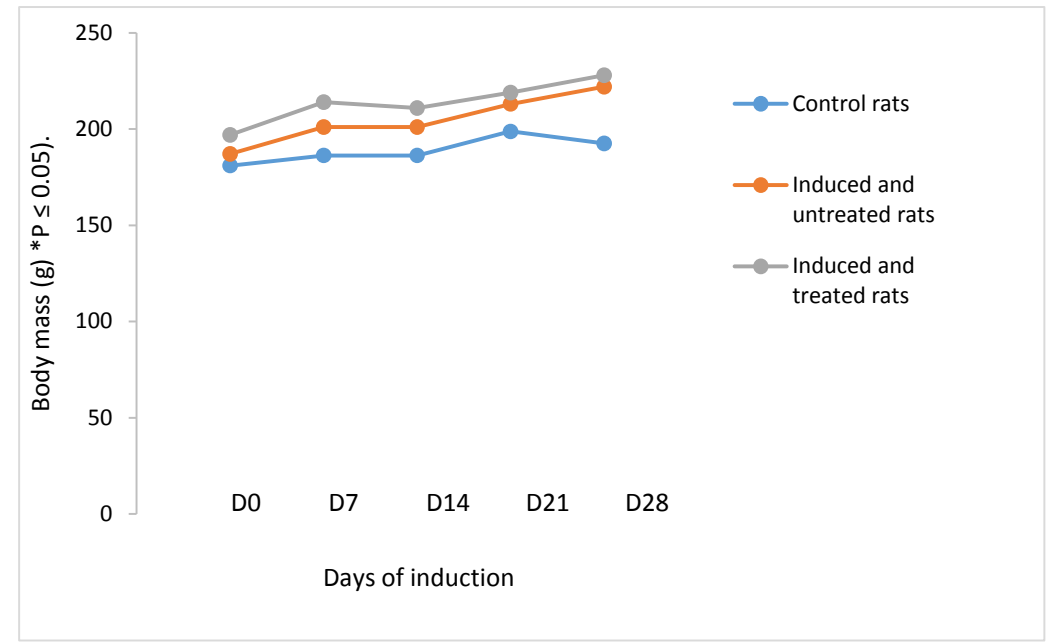

Figure 1. The body mass of rats during induction of hyperglycemia and hyperlipidemia.

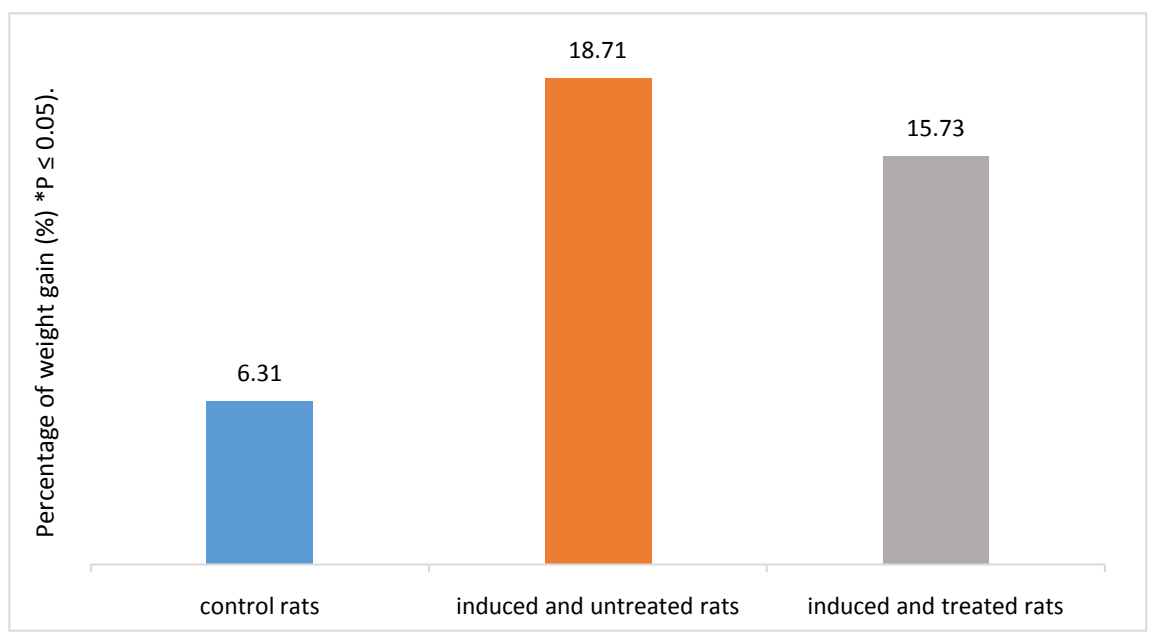

Figure 2. Percentage of weight gain at day 28.

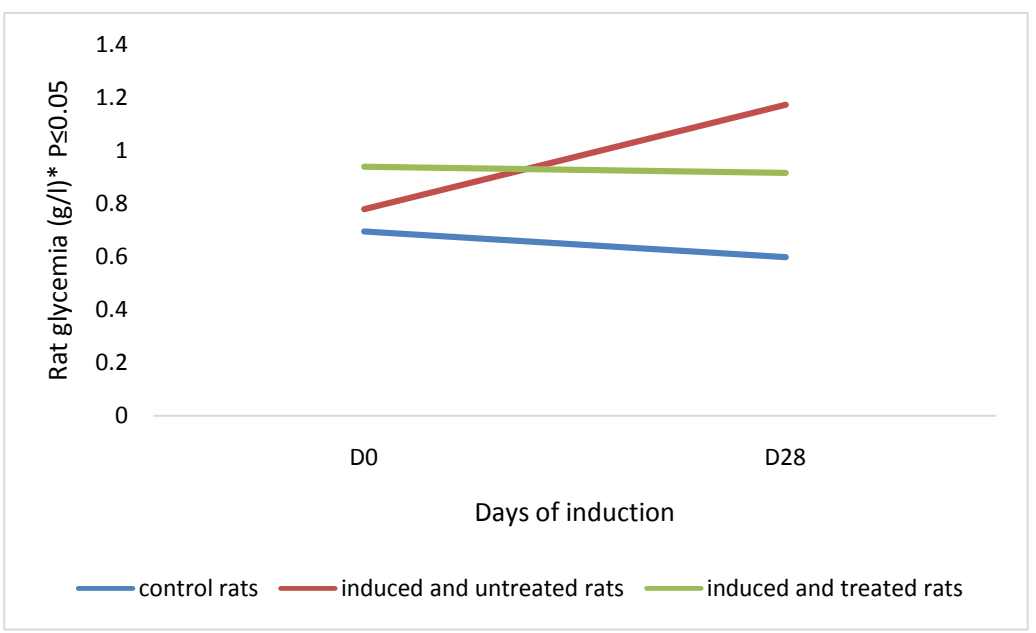

Figure 3. Evolution of blood glucose during induction of hyperglycemia and hyperlipidemia. 


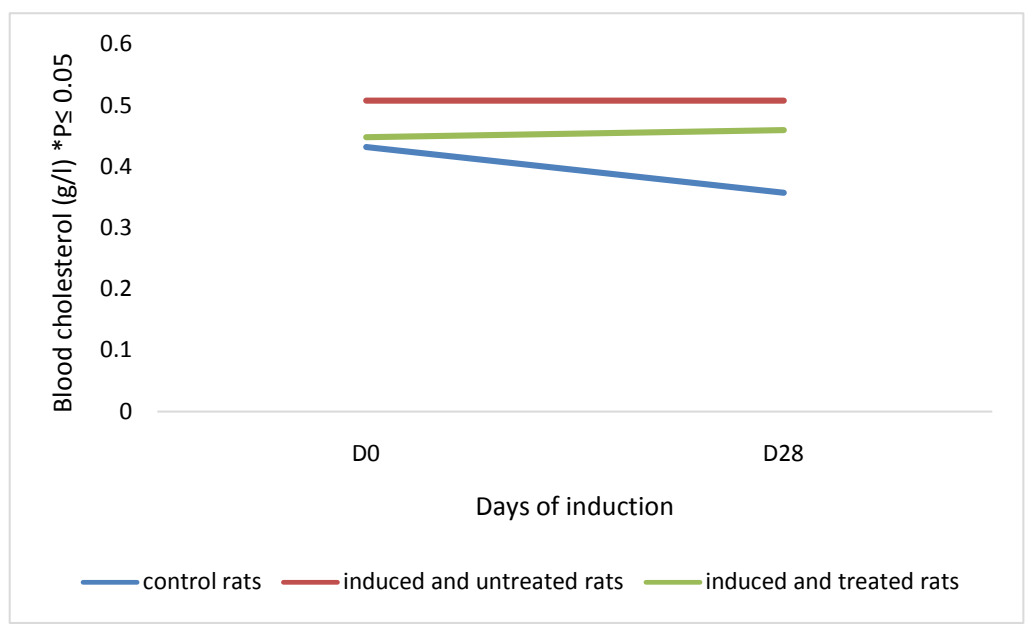

Figure 4. Evolution of blood cholesterol during induction of hyperglycemia and hyperlipidemia.

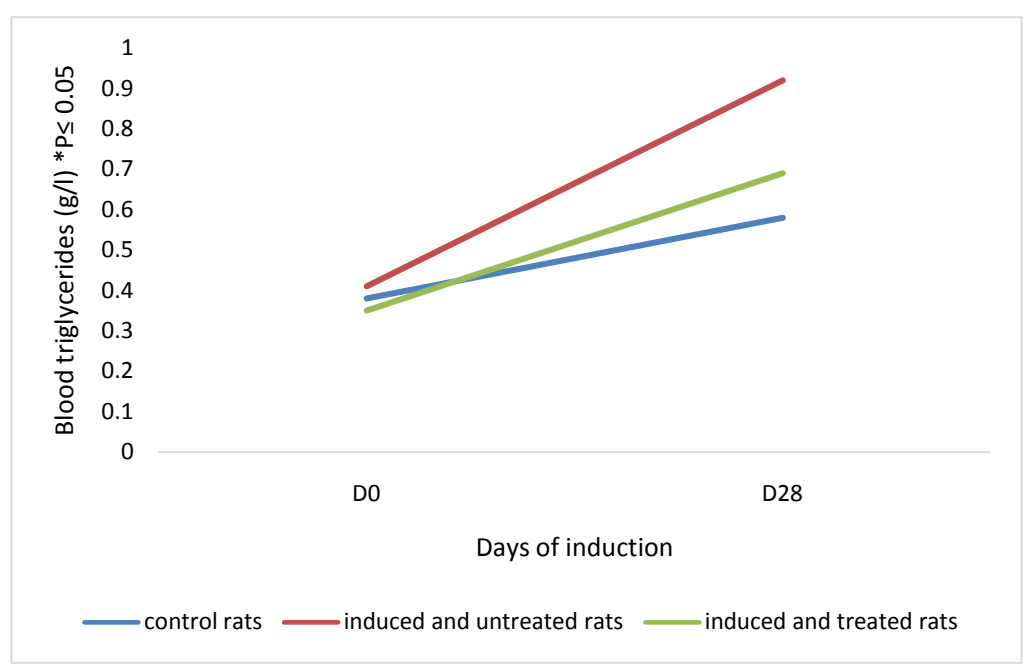

Figure 5. Evolution of blood triglyceride during induction of hyperglycemia and hyperlipidemia.

\subsection{Evaluation of the Therapeutic Effect of Tridax procumbens Ethyl Acetate Fraction (FETAC) against Hyperglycemia and Hyperlipidemia}

\subsubsection{Therapeutic Effect of Tridax procumbens Ethyl Acetate Fraction against Induced Hyperglycemia}

To evaluate the therapeutic effect of the ethyl acetate fraction (FETAC) of Tridax procumbens the induced and untreated rats (fatty hyperglycemic rats) were treated with $50 \mathrm{mg} / \mathrm{kg}$ of body weight of the fraction and were compared with the positive control rats (untreated fatty hyperglycemic rats) which were not treated with the fraction (Figure 6).

The blood sugar level did not change significantly neither in the untreated fatty hyperglycemic rats, nor in the fatty hyperglycemic rats treated with FETAC. (Were considered statistically significant the difference in the mean at $\mathrm{P} \leq$ $0.05)$. 

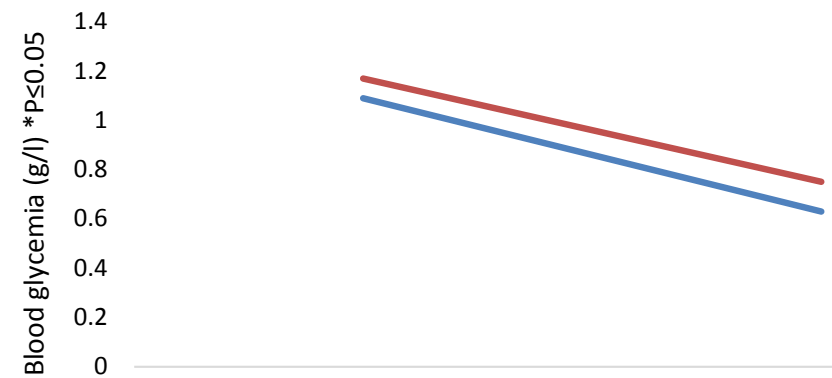

D15

Days of treatment with FETAC

untreated fatty hyperglycemic rats

fatty Hyperglycemic rats treated with FETAC

Figure 6. Effect of FETAC on the blood triglyceride of fatty hyperglycemic rats.

\subsubsection{Therapeutic Effect of Tridax procumbens Ethyl Acetate Fraction against Induced High Level of Triglyceride}

The induced and untreated rats (fatty hyperglycemic rats) with high level of triglyceride were treated with $50 \mathrm{mg} / \mathrm{kg}$ of body weight of the fraction and were compared with the positive control rats (untreated fatty hyperglycemic rats) which are not treated with the fraction (Figure 7).

The blood triglycerides level did not change significantly neither in the untreated fatty hyperglycemic rats, nor in the fatty hyperglycemic rats which were treated with FETAC (were considered statistically significant the difference in the mean at $\mathrm{P} \leq 0.05)$.

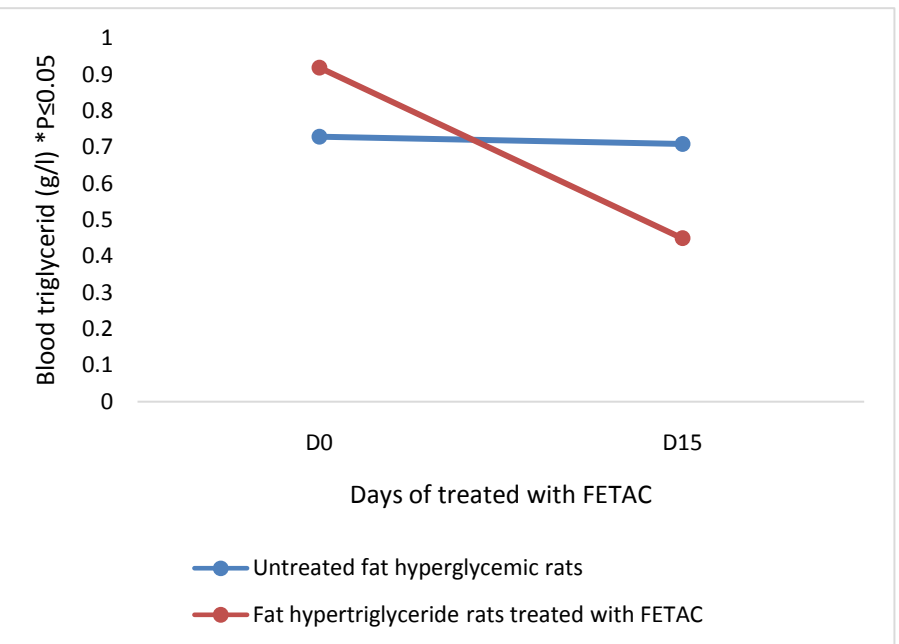

Figure 7. Effect of FETAC on the blood sugar of fatty hyperglycemic rats.

\section{Discussion}

The yields of the fractions of Tridax procumbens were very low compared to the yields of the fractions of Cochlospermum planchoni obtained by Koudoro et al. 
in 2014 [17] with the same method $(0.8 \%$ and $1.5 \%$ for the respective fractions of diethyl ether and ethyl acetate). We believe that this difference in yield could be due to the duration of the settling of the two phases and also to the number of repetitions of the liquid-liquid extraction.

- Evolution of rat weight during induction of hyperglycemia and hyperlipidemia

From the analysis of the Figure 1 and Figure 2, it appears that the average of the body mass of all rats increased over time. We observed in rats fed with the standard diet (control) a slight increase in body mass of $6.35 \%$. The rats which underwent induction of hyperglycemia and hyperlipidemia and not treated with Tridax procumbens extract (induced and untreated rats) had an increase in body mass of $18 \%$ while those which underwent induction and treated with Tridax procumbens at $500 \mathrm{mg} / \mathrm{kg}$ of body weight had an increase in body mass of 15\%. Treatment with tridax Procumbens extract during the induction resulted in a decrease of $3 \%$ in weight compared to the untreated rats. Tridax procumbens extract slightly prevents weight gain in wistar rats during induction. These results are in agreement with those of Keerthi et al. [20] who treated hyperlipidemic rats with doses of $250 \mathrm{mg}$ and $500 \mathrm{mg} / \mathrm{Kg}$ of body weight with the hydro-ethanolic extract of Tridax procumbens and observed a reduction of $6.0 \%$ and $3.5 \%$ respectively.

- Evolution of rat blood glucose during induction of hyperglycemia and hyperlipidemia

The analysis of the Figure 3 shows a non-significant variation in the blood glucose level in the control rats and a significant increase of $50.70 \%$ in the induced and not treated rats, in the induced treated rats there is an absence of change in blood sugar levels. From these results we can suggest that the hydroethanolic extract of Tridax procumbens can prevent hyperglycemia in rats subjected to a sweet and fatty diet. These results confirm those of several authors who have shown that the leaves and stems of Tridax procumbens have a hypoglycemic effect [21] [22] [23] [24] [25].

- Evolution of rat blood cholesterol during induction of hyperglycemia and hyperlipidemia

The analysis of Figure 4 shows that there is no significant variation in the cholesterol level neither in the control rats nor in the rats having undergone the induction of hyperglycemia and hyperlipidemia. We deduce that the duration of this diet did not allow the rats to develop hypercholesterolemia.

- Evolution of rat blood triglyceride during induction of hyperglycemia and hyperlipidemia

Figure 5 shows an increase in the level of triglycerides with a higher percentage in the induced and not treated rats. The level of triglycerides did not change neither in the control rats and nor in the induced and treated rats. The hydroethanolic extract inhibited the increase of triglyceride in the treated rats. This result is in accordance with other works which have showed that the administra- 
tion of the aqueous extract of Tridax procumbens to Wistars rats contributed to the significant reduction in the concentration of triglycerides [25].

- Therapeutic effect of Tridax procumbens ethyl acetate fraction against hyperglycemia

There is not a significant change in the blood sugar level neither in the untreated fatty hyperglycemic rats, nor in the fatty hyperglycemic rats treated with FETAC during the 15 days of treatment. There is no therapeutic effect observed with the FETAC fraction. It could be due to the very low yield of the fraction obtained after production.

- Therapeutic effect of Tridax procumbens ethyl acetate fraction against high level of triglyceride

There is not a significant change in the triglyceride level neither in the untreated fatty hyperglycemic rats, nor in the fatty hyperglycemic rats treated with FETAC during the 15 days of treatment. There is no therapeutic effect observed with the FETAC fraction. It could be due to the very low yield of the fraction obtained after production.

The preventive activity of Tridax procumbens extract against hyperglycemia and hyperlipidemia is demonstrated by our work and allow us to suggest a preventive activity of the plant against diabetes.

How Tridax Procumbens extract could prevent diabetes?

Hyperglycemia induces glucose autoxidation that generates hydroxyl radicals [26] and leads to the formation of advanced glycation products that influence the transcription of proinflammatory genes to promote further oxidative stress [27] [28]. In healthy subjects, hyperglycemia has been also associated with oxidative stress [29]. Nondiabetic rats that were infused with high levels of glucose and administered either of two antioxidants, that is, $\mathrm{N}$-acetylcysteine or taurine, did not develop insulin resistance despite being hyperglycemic, suggesting that oxidative stress may play a role in glucose induced insulin resistance and that this effect can be prevented by antioxidative factors [30]. Our previous work has shown that Tridax procumbens leaves contain a very high amount of vitamin $\mathrm{E}$ and flavonoids [15]. Vitamin $\mathrm{E}$ has been shown to have strong antioxidant and anti-inflammatory power. These two activities of vitamin $\mathrm{E}$ and flavonoids help prevent insulin resistance induced by oxidative stress and inflammation [31] [32] [33].

\section{Conclusion}

Tridax procumbens by its high content of vitamin $\mathrm{E}$ and flavonoids prevents diabetes and obesity by reducing the level of triglycerides and inhibiting the insulin resistance caused by hyperglycemia.

\section{Conflicts of Interest}

The authors declare no conflicts of interest regarding the publication of this paper. 


\section{References}

[1] Ministère de la santé du Bénin. Plan stratégique de lutte contre les maladies non transmissibles 2014-2018. Paragraphe 2. 15.

[2] OMS (2003) Rapport sur la santé dans le monde (façonner l'avenir). Rapport.

[3] Azaizeh, H., Fulder, S., Khalil, K. and Said, O. (2003) Ethnomedicinal Knowledge of Local Arab Practitioners in the Middle East Region. Fitoterapia, 74, 98-108. https://doi.org/10.1016/S0367-326X(02)00285-X

[4] Athanasiadou, S., Githiori, J. and Kyriazakis, I. (2007) Medicinal Plants for Helminth Parasite Control: Facts and Fiction. Animal, 1, 1392-1400. https://doi.org/10.1017/S1751731107000730

[5] Jahangir, M. (2001) Chemical and Biological Studies on Some Members of Asteraceae Family and Pseudocalymma elegans, a Native of Brazil. PhD Thesis, The International Center for Chemical Sciences, H.E.J. Research Institute of Chemistry, Karachi.

[6] Tiwari, U., Rastogi, B., Singh, P., Saraf, D.K. and Vyas, S.P. (2004) Immunomodulatory Effects of Aqueous Extract of Tridax procumbens in Experimental Animals. Journal of Ethnopharmacology, 92, 113-119. https://doi.org/10.1016/j.jep.2004.02.001

[7] Bhagwat, D.A., Killedar, S.G. and Adnaik, R.S. (2008) Antidiabetic Activity of Leaf Extract of Tridax procumbens. International Journal of Green Pharmacy, 2, 126-128. https://doi.org/10.4103/0973-8258.41188

[8] Hemalatha, R. (2008) Anti-Hepatotoxic and Anti-Oxidant Defence Potential of Tridax procumbens. International Journal of Green Pharmacy, 2, 164-169. https://doi.org/10.4103/0973-8258.42736

[9] Mundada, S. and Shivhare, R. (2010) Pharmacology of Tridax procumbens a Weed: Review. International Journal of Pharm Tech Research, 2, 1391-1394

[10] Pai, C., Kulkarni, U., Borde, M., Murali, S., Mrudula, P. and Deshmukh, Y. (2011) Antibacterial Activity of Tridax procumbens with Special. British Journal of Pharmaceutical Research, 1, 164-173. https://doi.org/10.9734/BJPR/2011/763

[11] Appiah-Opong, R., Nyarko, A.K., Dodoo, D., Gyang, F.N., Karam, K.A. and Ayisi, N.K. (2011) Antiplasmodial Activity of Extracts of Tridax procumbens and Phyllanthus amarus in in Vitro Plasmodium Falciparum Culture Systems. Ghana Medical Journal, 45, 143-150.

[12] Vishnu Priya, P., Radhika, K., Sivakumar, R., Sri Ramchandra, M., Prameela Devi, V. and Srinivas Rao, A. (2011) Evaluation of Anticancer Activity of Tridax procumbens Flower Extracts on PC 3 Cell Lines. Pharmanest, 2, 28-30.

[13] Koukoui, O., Sohounhloue, D., et al. (2015) Chemical Profile, Cytotoxicity Anti-Radical and Hypolipidemic Activities of Tridax procumbens of Benin. Research Journal of Pharmaceutical, Biological and Chemical Sciences, 6, 1441-1449.

[14] Chen, W.H., Ma, X.M., Wu, Q.X., et al. (2000) Chemical Constituent Diversity of Tridax procumbens. Canadian Journal of Chemistry, 86, 892-898. https://doi.org/10.1139/v08-097

[15] Koukoui, O., Medegan, S., Senou, M., Guinra, A., Koumayo, F., Adjagba, M., Agbagnan, P., Laleye, A. and Sezan, A. (2016) Effect of Tridax procumbens Hydroethanolic Extract on Wistar Rats Blood Glucose, Total Cholesterol, and Triglycerides. International Journal of Pharmacy and Biological Sciences, 6, 42-50. https://doi.org/10.21276/ijpbs.2016.6.4.6

[16] Alain, K.Y., Oronce, D.L.S., Mahudro, Y., Pascal, A.D.C., Paul, T.F., Alain, A.G., 
Félicien, A. and Koko, S.D.C. (2014) Caractérisation chimique, activités antiradicalaire and antibactérienne des extraits de l'écorce de racine de Cochlospermum planchoni du Bénin. Université d Abomey-Calavi International Journal of Innovation and Applied Studies, 7, 1582-1594.

[17] Weiss, J., Taylor, G. and Nebendah, L.K. (2000) Collection of Body Fluids. In: Krinke, G.J., Ed., The Laboratory Rat, the Handbook of Experimental Animal, Academic Press, Cambridge, Vol. 25, 485-495.

https://doi.org/10.1016/B978-012426400-7.50064-9

[18] Fasce, C.F. (1982) Enzymatic Colorimetric Method Determination of Total Cholesterol in Human Serum. Clinical Chemistry, 28, 901-907.

[19] Sammeta, K., Kota, P., Panda, J., et al. (2014) Anti-Hyperlipidemic Activity of Ethanolic Extract of Tridax procumbens L. International Journal of Pharmaceutical, Chemical and Biological Sciences, 4, 874-877.

[20] Sonawane, A., Srivastava, R.S., Sanghavi, N., Malode, Y. and Chavan, B. (2014) Anti-Diabetic Activity of Tridax procumbens. Journal of Scientific and Industrial Research, 3, 221-226.

[21] Ikewuchi, J.C. (2012) Alteration of Plasma Biochemical, Haematological and Ocular Oxidative Indices of Alloxan Induced Diabetic Rats by Aqueous Extract of Tridax procumbens Linn (asteraceae). EXCLI Journal, 11, 291-308.

[22] Pareek, H., Sharma, S., Khajja, B.S., Jain, K. and Jain, G.C. (2009) Evaluation Hypoglycemic and Anti-Hyperglycemic Potential of Tridax procumbens. BMC Complementary and Alternative Medicine, 9, 48.

https://doi.org/10.1186/1472-6882-9-48

[23] Bhagwat, D.A., Killedar, S.G. and Adnaik, R.S. (2008) Antidiabetic Activity of Leaf Extract of Tridax procumbens. International Journal of Green Pharmacy, 2, 126-128. https://doi.org/10.4103/0973-8258.41188

[24] Ikewuchi, C.J. and Ikewuchi, C.C. (2009) Alteration of Plasma Lipid Profile and Atherogenic Indices of Cholesterol Loaded Rats by Tridax procumbens Linn: Implications for the Management of Obesity and Cardiovascular Diseases. Biokemistri, 21, 95-99. https://doi.org/10.4314/biokem.v21i2.56477

[25] Turko, I.V., Marcondes, S. and Murad, F. (2001) Diabetes-Associated Nitration of Tyrosine and Inactivation of Succinyl-CoA:3-Oxoacid CoA-Transferase. The American Journal of Physiology-Heart and Circulatory Physiology, 281, H2289-H2294. https://doi.org/10.1152/ajpheart.2001.281.6.H2289

[26] Ceriello, A. and Testa, R. (2009) Antioxidant Anti-Inflammatory Treatment in Type 2 Diabetes. Diabetes Care, 32, S232-S236. https://doi.org/10.2337/dc09-S316

[27] Douillet, C., Bost, M., Accominotti, M., Borson-Chazot, F. and Ciavatti, M. (1998) Effect of Selenium and Vitamin E Supplementation on Lipid Abnormalities in Plasma, Aorta, and Adipose Tissue of Zucker Rats. Biological Trace Element Research, 65, 221-236. https://doi.org/10.1007/BF02789098

[28] Marfella, R., Quagliaro, L., Nappo, F., Ceriello, A. and Giugliano, D. (2001) Acute Hyperglycemia Induces an Oxidative Stress in Healthy Subjects. Journal of Clinical Investigation, 108, 635-636. https://doi.org/10.1172/JCI13727

[29] Haber, C.A., Lam, T.K., Yu, Z., et al. (2003) N-acetylcysteine and Taurine Prevent Hyperglycemia-Induced Insulin Resistance in Vivo: Possible Role of Oxidative Stress. The American Journal of Physiology —Endocrinology and Metabolism, 285, E744E753. https://doi.org/10.1152/ajpendo.00355.2002

[30] Singh, U. and Jialal, I. (2004) Anti-Inflammatory Effects of Alpha-Tocopherol. Annals of the New York Academy of Sciences, 1031, 195-203. 
https://doi.org/10.1196/annals.1331.019

[31] Scott, J.A. and King, G.L. (2004) Oxidative Stress and Antioxidant Treatment in Diabetes. Annals of the New York Academy of Sciences, 1031, 204-213.

https://doi.org/10.1196/annals.1331.020

[32] Devaraj, S. and Jialal, I. (1999) $\alpha$-Tocopherol Decreases Interleukin- $1 \beta$ Release from Activated Human Monocytes by Inhibition of 5-Lipoxygenase. Arteriosclerosis, Thrombosis, and Vascular Biology, 19, 1125-1133.

https://doi.org/10.1161/01.ATV.19.4.1125

[33] Thomas, S.R. and Stocker, R. (2000) Molecular Action of Vitamin E in Lipoprotein Oxidation: Implications for Atherosclerosis. Free Radical Biology and Medicine, 28, 1795-1805. https://doi.org/10.1016/S0891-5849(00)00236-7 